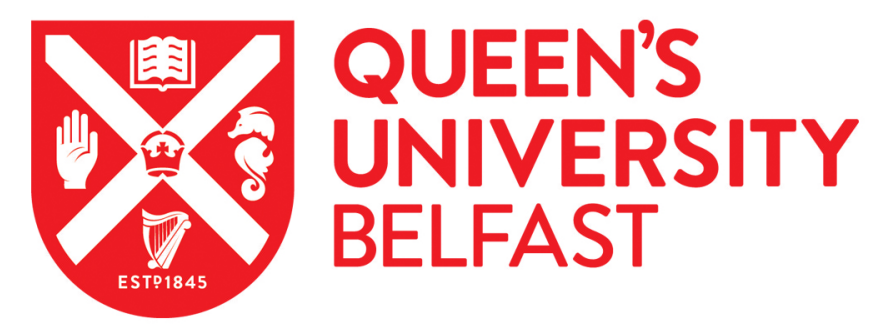

\title{
Preparation and surface modification of submicron YAl2 particles by mixed milling with magnesium for fabricating YAl2p/MgLiAl composites
}

Zhang, Q. Q., Wu, G. Q., Sha, W., Huang, Z., \& Tao, Y. (2014). Preparation and surface modification of submicron YAl2 particles by mixed milling with magnesium for fabricating YAI2p/MgLiAl composites. Powder Technology, 262, 209-214. https://doi.org/10.1016/j.powtec.2014.04.081

Published in:

Powder Technology

Document Version:

Peer reviewed version

Queen's University Belfast - Research Portal:

Link to publication record in Queen's University Belfast Research Portal

\section{General rights}

Copyright for the publications made accessible via the Queen's University Belfast Research Portal is retained by the author(s) and / or other copyright owners and it is a condition of accessing these publications that users recognise and abide by the legal requirements associated with these rights.

Take down policy

The Research Portal is Queen's institutional repository that provides access to Queen's research output. Every effort has been made to ensure that content in the Research Portal does not infringe any person's rights, or applicable UK laws. If you discover content in the Research Portal that you believe breaches copyright or violates any law, please contact openaccess@qub.ac.uk. 


\title{
Preparation and surface modification of submicron $\mathbf{Y A l}_{2}$ particles by mixed milling with magnesium for fabricating $\mathbf{Y A l}_{2 \mathrm{p}} / \mathrm{MgLiAl}$ composites
}

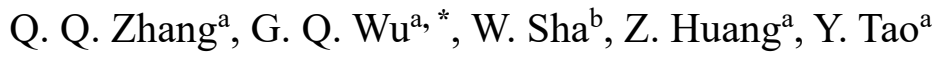

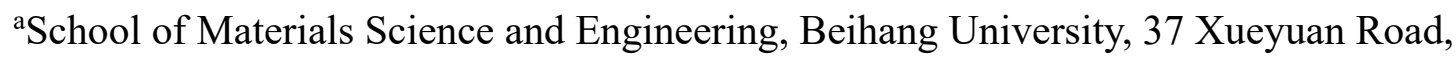 \\ Haidian District, Beijing 100191, China \\ bSchool of Planning, Architecture and Civil Engineering, Queen's University Belfast, \\ Belfast BT7 1NN, UK
}

\begin{abstract}
A new process for the preparation and surface modification of submicron $\mathrm{YAl}_{2}$ intermetallic particles was proposed to control the agglomeration of ultrafine $\mathrm{YAl}_{2}$ particles and interface in the fabrication of $\mathrm{YAl}_{2 \mathrm{p}} / \mathrm{MgLiAl}$ composites. The morphological and structural evolution during mechanical milling of $\mathrm{YAl}_{2}$ powders $(<30 \mu \mathrm{m})$ with magnesium particles $(\sim 100 \mu \mathrm{m})$ has been characterized by scanning electron microscopy, transmission electron microscopy, and X-ray diffraction. The results show that $\mathrm{YAl}_{2}$ particles are refined to submicron scale and separately cladded in magnesium coatings after mixed milling with magnesium particles for 20 hours. Mechanical and metallurgical bonds have been found in $\mathrm{YAl}_{2} / \mathrm{Mg}$ interfaces without any interface reactions. Both the refining and mechanical activation efficiencies for $\mathrm{YAl}_{2}$ particles are enhanced, which may be related to the addition of magnesium
\end{abstract}

\footnotetext{
* Corresponding author: Tel: +86 1082313240; E-mail: guoqingwu@buaa.edu.cn
} 
particles leading to atomic solid solution and playing a role as "dispersion stabilizer".

Keywords: Magnesium alloys; Composites; Intermetallics; Electron microscopy; Bonding; Interfaces

\section{Introduction}

Mg-Li based alloys and composites, known as the lightest metallic structural materials, have great potential for use not only in aerospace and military but also in automobiles and electrical appliances, due to their attractive features of high values of specific strength, specific modulus, and electromagnetic shielding properties [1-3]. $\mathrm{SiC}, \mathrm{Al}_{2} \mathrm{O}_{3}$ fibers, and $\mathrm{Mg}_{2} \mathrm{Si}$ particles [4-6] have been used to reinforce $\mathrm{Mg}$ - $\mathrm{Li}$ based alloys recently. The results show that the ceramic reinforcements are harmful to the ductility of the composites, as the chemical incompatibility between ceramic reinforcements and $\mathrm{Mg}$-Li alloy matrix remains a critical problem.

Wang et al. showed that $\mathrm{YAl}_{2}$ intermetallics have good physical and chemical compatibility with MgLiAl matrix, in Mg-Li matrix composites strengthened with the intermetallic compound $\mathrm{YAl}_{2}(25 \sim 37.5 \mu \mathrm{m})$ [7]. With the addition of $20 \%$ volume fraction $\mathrm{YAl}_{2}$ particles, the tensile strength increases to $225 \mathrm{MPa}$ and the elongation remains at $9 \%$. However, the strength is still low compared to some commercial aluminum alloys. When the volume fraction increases to $40 \%$, the advantage of low density for Mg-Li fades.

The composite mechanical properties increase with the decrease of reinforcement particle size, especially when the particle size is in submicron or nano range $[8,9]$. 
However, fine reinforcement particles are easy to agglomerate in matrix which may seriously affect the mechanical properties of the composites [10-12]. To overcome this problem, many methods were used to control micro particle agglomeration, such as mechanical stirring [13], ultrasonic dispersion [14], surface coating [15], and dispersing agents [16]. However, it is still a challenge for submicron or nano-sized particles. Mechanical alloying method was used to improve the reinforcement distribution in particle-reinforced metal matrix composites, especially for the nano-sized particles $[17,18]$. However, $\mathrm{Mg}$-Li matrix composites could not be prepared by mechanical alloying, because the powders can be easily oxidized. How to control the agglomeration for ultrafine particle-reinforced $\mathrm{Mg}$-Li composites is crucial. Zhang et al. proposed a pre-milling followed by stir casting method to control the agglomeration of ultrafine $\mathrm{YAl}_{2}$ particles in $\mathrm{YAl}_{2 \mathrm{p}} / \mathrm{MgLiAl}$ composite. The strength was significantly improved to $220 \mathrm{MPa}$ with the addition of $5 \mathrm{vol} \% \mathrm{YAl}_{2}$ particles $(<3 \mu \mathrm{m})$ [19]. It shows a very good prospect for the Mg-Li matrix composites development. However, neither the pre-milling process nor control mechanism in the method has been further studied.

In the present work, submicron $\mathrm{YAl}_{2}$ particles have been prepared by mechanical milling with and without magnesium particles at ambient temperature. The effects of milling on the surface modification and dispersion of $\mathrm{YAl}_{2}$ particles in $\mathrm{YAl}_{2} / \mathrm{Mg}$ mixture were characterized. The influence of the milling time on the particles size and crystal structure during mechanical milling was investigated by scanning electron microscopy (SEM), transmission electron microscopy (TEM), and X-ray diffraction (XRD). The $\mathrm{YAl}_{2} / \mathrm{Mg}$ interfacial evolution was observed. The effect of magnesium 
particle addition on the morphological and structural evolution is further discussed.

\section{Experimental methods}

\subsection{Materials and milling procedure}

$\mathrm{YAl}_{2}$ ingots $(99.9 \%$ pure) were obtained from General Research Institute for Nonferrous Metals by melting pure yttrium and aluminum. The ingots were crushed and then mechanically milled to about $30 \mu \mathrm{m}$ in a planetary ball milling device (QM-1SP). Agate balls and tanks were used. The ball to powder weight ratio was approximately $4: 1$. The rotation speed (cup speed) was $400 \mathrm{rpm}$. The magnesium particles $(99.9 \%$ pure, $\sim 100 \mu \mathrm{m})$ were sawn from magnesium ingots.

The $\mathrm{YAl}_{2}$ particles $(\sim 30 \mu \mathrm{m})$ were further milled at ambient temperature in the same milling device and parameters, without (route 1) and with magnesium particles (route 2). The ball to powder weight ratio was approximately $8: 1$, and the rotation speed (cup speed) was $400 \mathrm{rpm}$. The mixed materials were ball-milled up to $30 \mathrm{~h}$ with several interruptions to open the vial and take out a small portion of particles for analysis. Samples were collected at shorter milling times (2, 10, 20, and $30 \mathrm{~h})$, so that the evolution of the particles during milling could be followed.

\subsection{Microstructure characterization}

The morphological evolution of particles during milling was characterized by SEM (S-4800) and TEM (JEM-2100). The particle size evolution was characterized using IPP software based on five SEM images, for each condition. For microstructural study on the cross-section and interface of the $\mathrm{YAl}_{2} / \mathrm{Mg}$ mixed particles, the mixed 
particles were hot mounted with bakelite powders. Then, the samples were ground by No. 2000 sandpaper and polished with $0.5 \mu \mathrm{m} \mathrm{Al}{ }_{2} \mathrm{O}_{3}$ slurry. An SEM (Quanta 200F) was used to observe the section morphology of the mixed particles. There is no bakelite showing in micrographs because all the particles were pressed to a block sample before hot mounting. All SEM samples were gold coated to make them conductive.

Following the milling, the particles were characterized by XRD with $\mathrm{Cu} \mathrm{K} \alpha$ radiation (XRD-MAC Science M21X). The crystallite size and lattice strain of specimens were calculated from XRD patterns using the Williamson-Hall method as follows [20]:

$$
\mathrm{B} \cos \theta=0.9 \lambda / \mathrm{D}+2 \varepsilon \sin \theta
$$

where $\mathrm{B}, \theta, \lambda, \mathrm{D}$, and $\varepsilon$ are full width at half maximum (FWHM), peak position, the wave length $(0.15406 \mathrm{~nm})$, crystallite size, and lattice strain, respectively.

\section{Results and discussion}

\subsection{Morphological changes}

Fig. 1 presents the morphology of particles before mixed milling. The initial $\mathrm{YAl}_{2}$ powder consists of irregular shaped particles with various sizes from 1 to $30 \mu \mathrm{m}$. The magnesium particles are in polyhedral shape with particle sizes of about 50 100 $\mu \mathrm{m}$.

The morphological evolution of $\mathrm{YAl}_{2}$ particles after milling respectively through route 1 and route 2 is shown in Fig. 2 a and Fig. 2b. For route 1, after milling, the $\mathrm{YAl}_{2}$ particles are refined in a regular-rounded morphology. In route 2 , the $\mathrm{YAl}_{2} / \mathrm{Mg}$ mixed 
particles appear similar to that of route 1 but with a smaller particle size. The variation in the surface morphologies of the particle samples after being ball-milled is shown in higher magnification. Compared to route 1 (Fig. 2a), we can see that $\mathrm{YAl}_{2}$ is cladded by Mg scraps, forming a kind of mixed particles with rough surface (Fig. 2b), for the reason that ductile $\mathrm{Mg}$ particles underwent intense plastic deformation and formed layers of wrapping due to the ball impact.

The morphology and cross-section micrographs of the $\mathrm{YAl}_{2} / \mathrm{Mg}$ mixed particles during the mixed milling are presented in Fig. 3. After milling for $10 \mathrm{~h}, \mathrm{YAl}_{2}$ was cladded in magnesium wrapping, forming series of coarse mixed particles with irregular shape (Fig. 3a). These mixed particles had a mean diameter of about $10 \mu \mathrm{m}$ and consisted of two phases (Fig. 3b). Further, continuous and severe repetitive impacts of the milling media in longer milling times caused the particles to break into smaller pieces. Partially agglomerated $\mathrm{YAl}_{2}$ particles were deagglomerated. At the milling of $20 \mathrm{~h}$, the mixed particles were refined with a mean diameter of about $1 \mu \mathrm{m}$ (Fig. 3c). The corresponding energy dispersive spectrometry analyses, Fig. 3e and Fig. 3f, respectively, of positions $\mathrm{A}$ and $\mathrm{B}$ in Fig. $3 \mathrm{~d}$ suggest that the white phase is $\mathrm{YAl}_{2}$ because of the higher content of yttrium element with a higher atomic weigh compared to magnesium. It can be seen that $\mathrm{YAl}_{2}$ particles are refined to submicron scale and separately cladded in magnesium coatings after mixed milling for $20 \mathrm{~h}$. The morphology of mixed particles changes to very homogeneous near-spherical shape, and good metallurgical bond is obtained between $\mathrm{YAl}_{2}$ particles and elemental magnesium. 
In the samples for cross-section observation, the interface mixed milled for $10 \mathrm{~h}$ after hot mounting is still at the mechanical embedding stage, which means that the hot mounting could not change the interface bonding from mechanical to metallurgical bonding. This means that the effect of hot mounting on the $\mathrm{YAl}_{2} / \mathrm{Mg}$ interface is limited, and maybe very small. The metallurgical bonding resulted from the milling process. Although hot mounting reached $140^{\circ} \mathrm{C}$ with forces, it lasted for only less than $10 \mathrm{~min}$. Under this condition, the effect on the interfaces may be neglected.

\subsection{Interfacial evolution for $\mathrm{YAl}_{2} / \mathrm{Mg}$}

Further characterization of the $\mathrm{YAl}_{2} / \mathrm{Mg}$ interface of mixed particles during mixed milling is shown in Fig. 4. During the milling process, the ductile Mg particles underwent intense plastic deformation and formed layers of wrapping due to the ball impacts. $\mathrm{YAl}_{2}$ particles adhered and were mechanically embedded into the magnesium wrapping, forming mechanical bond interface (Fig. 4a). With further milling, element diffusion might have happened between $\mathrm{YAl}_{2}$ intermetallics and magnesium coatings.

The SEM-BSE imaging, in Fig. 4b, suffers from a resolution issue, because the backscattered electrons can come from sub surface, after the incident electron beam has scattered. So, the gradual contrast, between the particle and $\mathrm{Mg}$, labeled "bond" in Fig. $4 \mathrm{~b}$, in a brightness between that of the particle and that of $\mathrm{Mg}$, could be the result of averaging.

Meanwhile, coarse $\mathrm{YAl}_{2}$ particles fracture and some interface decohesion appear to have happened between $\mathrm{YAl}_{2}$ and $\mathrm{Mg}$ matrix during further milling (Fig. 4b). When welding and fracture mechanisms reach a balance, $\mathrm{YAl}_{2} / \mathrm{Mg}$ interface bond will 
gradually change from mechanical bond to metallurgical bond. If the mixed particles are added into the melted LA143 matrix, the coatings would (partially) dissolve first. Then, the $\mathrm{YAl}_{2}$ particles may adhere better to the metal matrix, resulting in stronger particle/matrix interface formation.

TEM observation indicates that after milling for $20 \mathrm{~h}$, the brittle phase $\left(\mathrm{YAl}_{2}\right.$ particles) is incorporated in the ductile phase $(\mathrm{Mg})$ through ball milling. Good metallurgical bond is obtained between $\mathrm{YAl}_{2}$ particles and elemental magnesium. The $\mathrm{YAl}_{2} / \mathrm{Mg}$ interface is clear and free from any interfacial reactions and bonds directly (Fig. 5a). Fig. 5b gives HRTEM image of the $\mathrm{YAl}_{2} / \mathrm{Mg}$ mixture along the [114] orientation of the $\mathrm{YAl}_{2}$ particles and the [2110] orientation of the elemental magnesium. It can be seen that the $\mathrm{YAl}_{2}$ particle and magnesium coating bond on the atomic scale, and some atomic disorder exists in the interface region (marked by the arrow) that may be generated by ball milling.

\subsection{Particle size distribution}

Fig. 6 shows the frequency distributions of $\mathrm{YAl}_{2}$ particle size milled in route 1 and route 2 for different times. It can be seen that, for route 1 (Fig. 6a), as the milling time increases from $0 \mathrm{~h}$ to $20 \mathrm{~h}$, not only does the frequency distribution peak shift to smaller particle size regions, but also the particle size distributes more narrowly. After milling for $10 \mathrm{~h}$, the particle mean diameter is $0.9 \mu \mathrm{m}$. Compared to the trend in route 1, the frequency distribution of $\mathrm{YAl}_{2}$ particle size in route 2 (Fig. 6b) shifts to smaller particle size regions with an anomaly at the milling time of $10 \mathrm{~h}$, because the hard fine $\mathrm{YAl}_{2}$ particles are randomly embedded into the deformed, soft magnesium matrix to 
form coarse mixed $\mathrm{YAl}_{2} / \mathrm{Mg}$ particles at the milling time of $10 \mathrm{~h}$, as shown in Fig. 3. Fracturing becomes a significant process for mixed particles with further milling, which leads to a decrease in particle size. Beyond the milling of $20 \mathrm{~h}$, the particle size virtually has no change.

Moreover, detailed analysis for Fig. 6a and Fig. 6b reveals a variation of frequency distribution of submicron particle size after milling for $30 \mathrm{~h}$. The frequency distribution peak shifts to and stabilizes at the $0.5-1 \mu \mathrm{m}$ position in route 1 , while the peak stabilizes at the $<0.5 \mu \mathrm{m}$ position in route 2 , which supports the SEM observations in Fig. 2. It reveals that the addition of magnesium particles improves the refining of $\mathrm{YAl}_{2}$ particles.

\subsection{Structural evolution}

The XRD patterns of particles produced from routes 1 and 2 at various milling times are shown in Fig. 7. No oxidation reaction or new phases can be detected after milling in both routes. Severe plastic deformation of the particles can lead to grain refining, accumulation of internal stress, change of the lattice parameter, and formation of cell structure [21]. It is observed that the $\mathrm{XRD}$ peak of $\mathrm{YAl}_{2}$ and magnesium particles are lowered and broadened during the milling process, which indicates that both routes have significant effect in reducing the crystallite size and accumulation of lattice strain. This can also be revealed from the TEM and HRTEM morphology as shown in Fig. 5. The absence of the diffraction peaks of magnesium element is probably due to its small amount and weak X-ray scattering intensity.

The lattice strain and grain size of $\mathrm{YAl}_{2}$ as a function of milling time were 
calculated according to the Williamson-Hall method, and the results are shown in Fig. 8. It can be seen that the crystallite size decreases (Fig. 8a) but lattice strain increases (Fig. 8b) with increasing milling time. The two parameters appear to approach a constant value after the milling time of $10 \mathrm{~h}$ in route 1 . Compared to route 1 , approaching steady state is delayed to after the milling time of $20 \mathrm{~h}$ in route 2 . Meanwhile, smaller crystal size and higher lattice strain of $\mathrm{YAl}_{2}$ particles in route 2 are obtained than those of route 1 . Surface modification through ball milling has a significant effect on the structure evolution and particle distribution in the matrix due to the atomic solution or dispersion stability [22-24]. Magnesium coating on the $\mathrm{YAl}_{2}$ particles might have diffused into $\mathrm{YAl}_{2}$ during the ball milling, and might also play a role of "dispersion stabilizer", which can promote both the refining and mechanical activation behavior. As a result, the efficiency of mechanical activation for $\mathrm{YAl}_{2}$ particles is enhanced by ball milling with the addition of magnesium particles. Submicron $\mathrm{YAl}_{2}$ particles and surface modification, produced by mixed milling with magnesium particles for 20 hours, should be beneficial to the wettability and interface bonding between $\mathrm{YAl}_{2}$ reinforcements and $\mathrm{MgLiAl}$ matrix. When the $\mathrm{YAl}_{2} / \mathrm{Mg}$ mixed particles are used as reinforcements in the composites fabrication, they should more uniformly distribute in the matrix and should result in excellent mechanical properties.

\section{Conclusions}

In this study, a new process for preparation and surface modification of submicron $\mathrm{YAl}_{2}$ particles by mixed milling with magnesium particles was developed 
for the fabrication of $\mathrm{YAl}_{2 \mathrm{p}} / \mathrm{MgLiAl}$ matrix composites. The main results are as follows:

(1) The $\mathrm{YAl}_{2}$ particles were refined to submicron scale and separately cladded in magnesium coatings after mixed milling for 20 hours. After that, the morphology of the $\mathrm{YAl}_{2} / \mathrm{Mg}$ mixed particles changed to homogeneous spheres with a mean size below $1 \mu \mathrm{m}$.

(2) Mechanical and metallurgical bonds have been found in $\mathrm{YAl}_{2} / \mathrm{Mg}$ interfaces without any interface reactions. After long mixed milling, mechanical bond transformed into metallurgical bond possibly by element diffusion between $\mathrm{YAl}_{2}$ intermetallics and magnesium coatings.

(3) The efficiencies of both refining and mechanical activation are enhanced by the milling with magnesium particles, which may be related to the addition of magnesium particles leading to atomic solid solution and playing a role as “dispersion stabilizer".

(4) It may be possible to achieve uniformly distributed microstructure of the $\mathrm{YAl}_{2} / \mathrm{LA} 143$ composites and excellent mechanical properties with the submicron $\mathrm{YAl}_{2}$ particles and surface modification produced by mixed milling with magnesium particles.

\section{Acknowledgements}

This paper is financially supported by the Natural Science Foundation of China

(Grant No. 50901005) and the Fund of Aeronautics Science (Grant No. 
2010ZF51068).

\section{References}

[1] T. Al-Samman: 'Comparative study of the deformation behavior of hexagonal magnesium-lithium alloys and a conventional magnesium AZ31 alloy', Acta Mater., $2009,57,2242-2299$.

[2] T. Liu, S.D. Wu, S.X. Li, P.J. Li: 'Microstructure evolution of Mg-14\%Li-1\%Al alloy during the process of equal channel angular pressing', Mater. Sci. Eng. A, 2007, 460-461, 499-503.

[3] W.J. Kim, M.J. Kim, J.Y. Wang: 'Ultrafine-grained Mg-9Li-1Zn alloy sheets exhibiting low temperature superplasticity', Mater. Sci. Eng. A, 2009, 516, 17-22.

[4] H.S. Yu, R.L. Gao, G.H. Min, Z.F. Wang, X.C. Chen: 'Mechanical properties and creep resistance of $\mathrm{Mg}$ - $\mathrm{Li}$ composites reinforced by $\mathrm{MgO} / \mathrm{Mg} 2 \mathrm{Si}$ particales', Trans. Nonferrous Met. Soc. China, 2002, 12, 1154-1157.

[5] S. Kúdela Jr., H. Wendrock, S. Kúdela, A. Pawełek, A. Piatkowski, K. Wetzig: 'Fracture behavior of Mg-Li matrix composites', Int. J. Mater. Res., 2009, 100, $910-914$.

[6] Z. Trojanová, Z. Drozd, S. Kúdela, Z. Száraz, P. Lukáč: 'Strengthening in Mg-Li matrix composites', Compos. Sci. Technol., 2007, 67, 1965-1973.

[7] S.J. Wang, G.Q. Wu, Z.H. Ling, Z. Huang: 'Microstructure and mechanical properties of $\mathrm{YAl}_{2}$ reinforced MgLiAl composite', Mater. Sci. Eng. A, 2009, 518, $158-161$. 
[8] Z. Zhang, D.L. Chen: 'Consideration of Orowan strengthening effect in particulate-reinforced metal matrix nanocomposites: A model for predicting their yield strength', Scr. Mater., 2006, 54, 1321-1326.

[9] M. Rahimian, N. Parvin, N. Ehsani: 'Investigation of particle size and amount of alumina on microstructure and mechanical properties of Al matrix composite made by powder metallurgy', Mater. Sci. Eng. A, 2010, 527, 1031-1038.

[10] Z.W. Wang, M. Song, C. Sun, Y.H. He: 'Effects of particle size and distribution on the mechanical properties of $\mathrm{SiC}$ reinforced $\mathrm{Al}-\mathrm{Cu}$ alloy composites', Mater. Sci. Eng. A, 2011, 528, 1131-1137.

[11] Y.C. Kang, S.L.I. Chan: 'Tensile properties of nanometric $\mathrm{Al}_{2} \mathrm{O}_{3}$ particulate-reinforced aluminum matrix composites', Mater. Chem. Phys., 2004, 85, $438-443$.

[12] A. Ayyar, N. Chawla: 'Microstructure-based modeling of the influence of particle spatial distribution and fracture on crack growth in particle-reinforced composites', Acta Mater., 2007, 55, 6064-6073.

[13] M.C. Gui, J.M. Han, P.Y. Li: 'Microstructure and mechanical properties of $\mathrm{Mg}-\mathrm{A} 19 \mathrm{Zn} / \mathrm{SiC}_{\mathrm{p}}$ composite produced by vacuum stir casting process', Mater. Sci. Technol., 2004, 20, 765-771.

[14] H. Su, W.L. Gao, Z.H. Feng, Z. Lu: 'Processing, microstructure and tensile properties of nano-sized $\mathrm{Al}_{2} \mathrm{O}_{3}$ particle reinforced aluminum matrix composites', Mater. Des., 2012, 36, 590-596.

[15] Z.Q. Yu, G.H. Wu, L.T. Jiang, D.L. Sun: 'Effect of coating $\mathrm{Al}_{2} \mathrm{O}_{3}$ reinforcing 
particles on the interface and mechanical properties of 6061 alloy aluminium matrix composites', Mater. Lett., 2005, 59, 2281-2284.

[16] D. Liu, Y. Yan, K. Lee, J. Yu: 'Effect of surfactant on the alumina dispersion and corrosion behavior of electroless Ni-P- $\mathrm{Al}_{2} \mathrm{O}_{3}$ composite coatings', Mater. Corros., 2009, 60, 690-694.

[17] M.F. Zawrah, H.A. Zayed, Raghieba A. Essawy, A.H. Nassar, M.A. Taha: 'Preparation by mechanical alloying, characterization and sintering of $\mathrm{Cu}-20$ wt.\% $\mathrm{Al}_{2} \mathrm{O}_{3}$ nanocomposites', Mater. Des., 2013, 46, 485-490.

[18] S.S. Razavi Tousi, R. Yazdani Rad, E. Salahi, I. Mobasherpour, M. Razavi: 'Production of $\mathrm{Al}-20$ wt.\% $\mathrm{Al}_{2} \mathrm{O}_{3}$ composite powder using high energy milling', Powder Technol., 2009, 192, 346-351.

[19] X. Zhang, G.Q. Wu, Z.H. Ling, Z. Huang: 'A novel method to control agglomeration of ultrafine $\mathrm{YAl}_{2}$ particles in $\mathrm{YAl}_{2 \mathrm{p}} / \mathrm{MgLiAl}$ composite', Mater. Lett., 2011, 65, 104-106.

[20] G.K. Williamson, W.H. Hall: 'X-ray line broadening from field aluminium and wolfram', Acta Metall., 1953, 1, 22-31.

[21] C. Suryanarayana: 'Mechanical alloying and milling', Prog. Mater. Sci., 2001, 46, $1-184$.

[22] A. Albiter, E. Bedolla, R. Perez: 'Microstructure characterization of the NiAl intermetallic compound with $\mathrm{Fe}, \mathrm{Ga}$ and $\mathrm{Mo}$ additions obtained by mechanical alloying', Mater. Sci. Eng. A, 2002, 328, 80-86.

[23] M. Hedayati, M. Salehi, R. Bagheri, M. Panjepour, A. Maghzian: 'Ball milling 
preparation and characterization of poly (ether ether ketone)/surface modified silica nanocomposite', Powder Technol., 2011, 207, 296-303.

[24] M.H. Choi, N.H. Kim, J.H. Lim, S.Y. Kim, E.G. Chang: 'Agglomeration characteristic of particles in alumina slurry by addition of chemicals and milling process for Cu CMP', Mater. Sci. Eng. B, 2005, 118, 306-309. 


\section{Figure captions}

Fig.1. SEM micrographs for particles before mixed milling. (a) $\mathrm{YAl}_{2}$, (b) magnesium.

Fig.2. SEM micrographs for particles milled for $20 \mathrm{~h}$. (a) $\mathrm{YAl}_{2}$; (b) $\mathrm{YAl}_{2} / \mathrm{Mg}$

particles.

Fig.3. SEM micrographs and EDS analyses of the mixed particles after mixed milling for different times. (a) Morphology image, $10 \mathrm{~h}$; (b) cross-section BSE image, $10 \mathrm{~h}$; (c) morphology image, 20 h; (d) cross-section BSE image, 20 h; (e) EDS of location A; (f) EDS of location B.

Fig.4. SEM micrographs of the $\mathrm{YAl}_{2} / \mathrm{Mg}$ interface of mixed particles during surface modification. (a) Morphology image; (b) BSE image.

Fig.5. TEM (a) and HRTEM (b) images of $\mathrm{YAl}_{2} / \mathrm{Mg}$ particle after mixed milling.

Fig.6. Frequency distributions of $\mathrm{YAl}_{2}$ particle size in route 1 (a) and in route 2 (b), after different milling times. The distribution in (b) at $0 \mathrm{~h}$ is for $\mathrm{YAl}_{2} / \mathrm{Mg}$ mixed particles that include both $\mathrm{YAl}_{2}$ particles and Mg particles. At the beginning of mixed milling, the plastic $\mathrm{Mg}$ was deformed more severely. There were no $\mathrm{Mg}$ particles remaining after milling for $20 \mathrm{~h}$.

Fig.7. XRD pattern evolution during milling for route 1 (a) and route 2 (b).

Fig.8. Crystal size (a) and lattice strain (b) evolution of $\mathrm{YAl}_{2}$ during milling for route 1 and route 2 . 


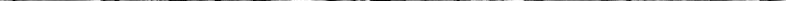




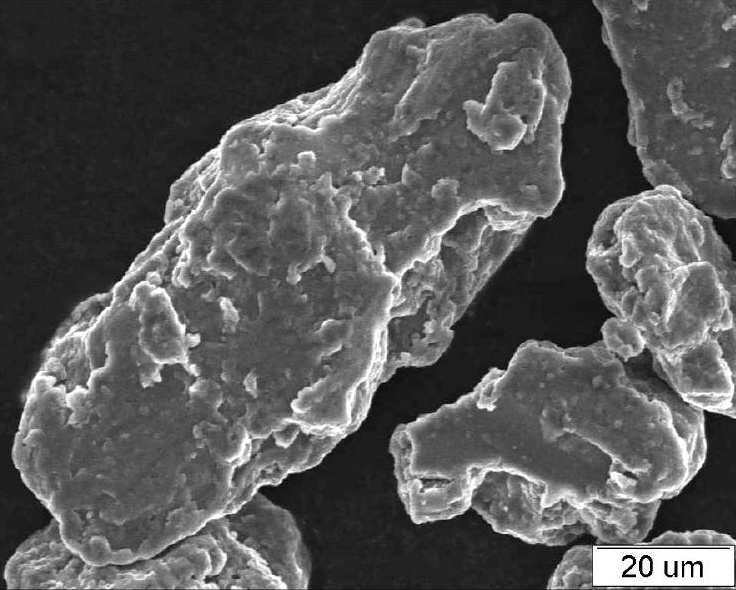




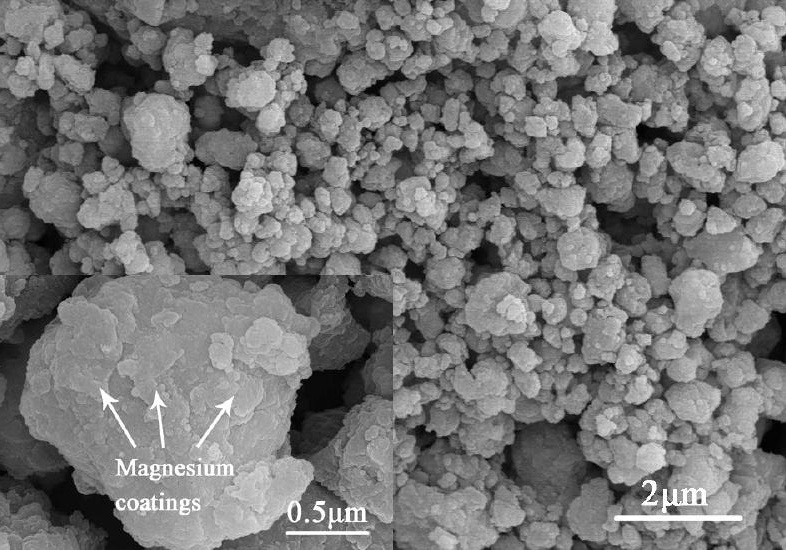




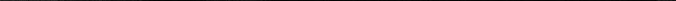




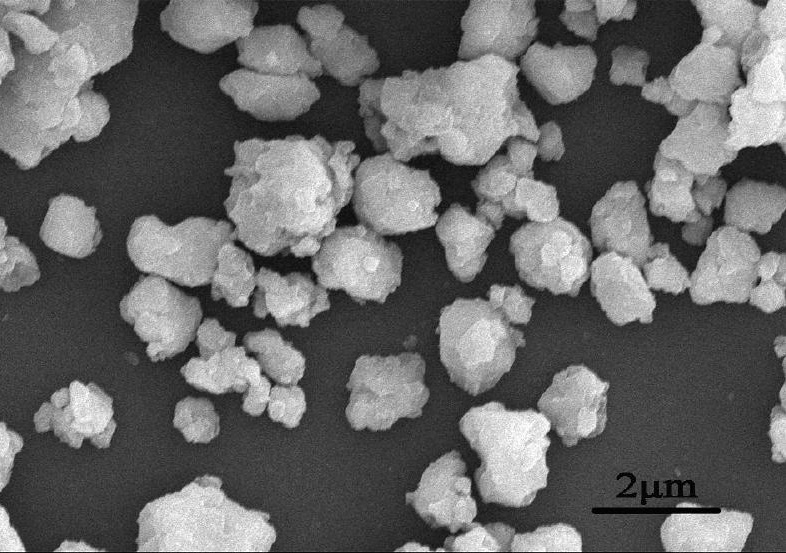




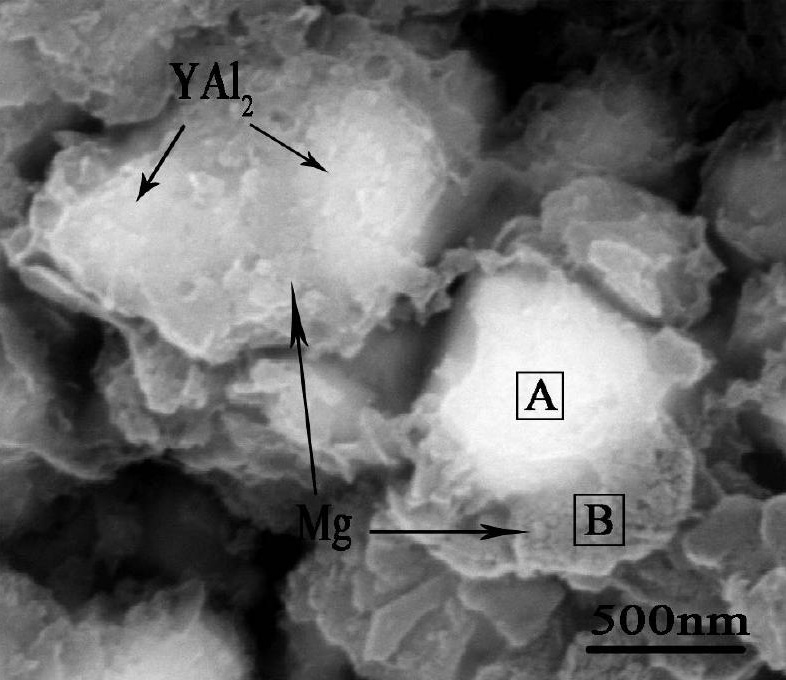




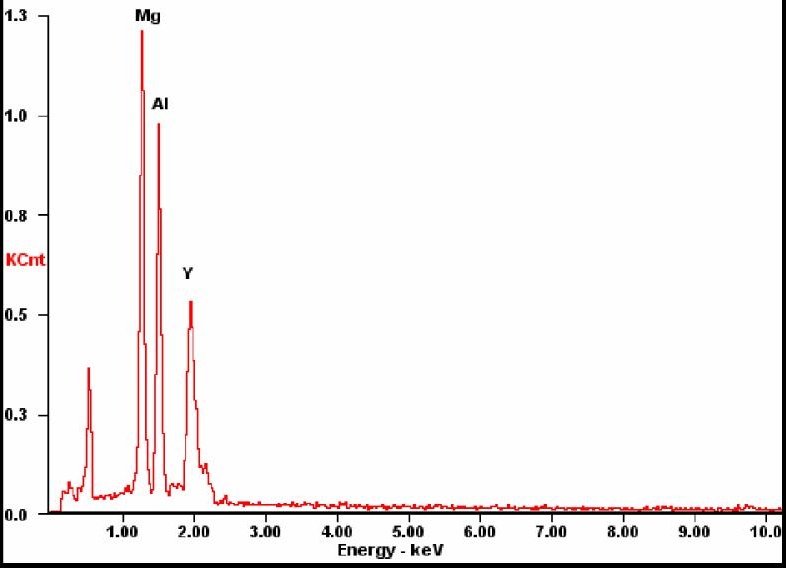




\section{$\mathrm{YAl}_{2}$}

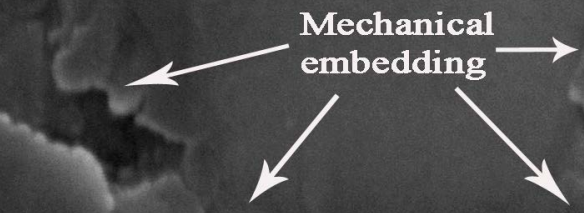

Mg 

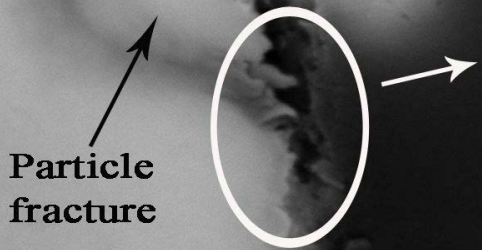

Interface decohesion

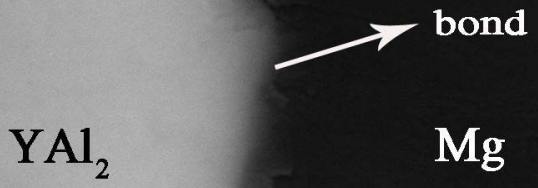

$1 \mu \mathrm{m}$ 
$\mathrm{YAl}_{2}$

Mg

$\overline{30 \mathrm{~nm}}$ 

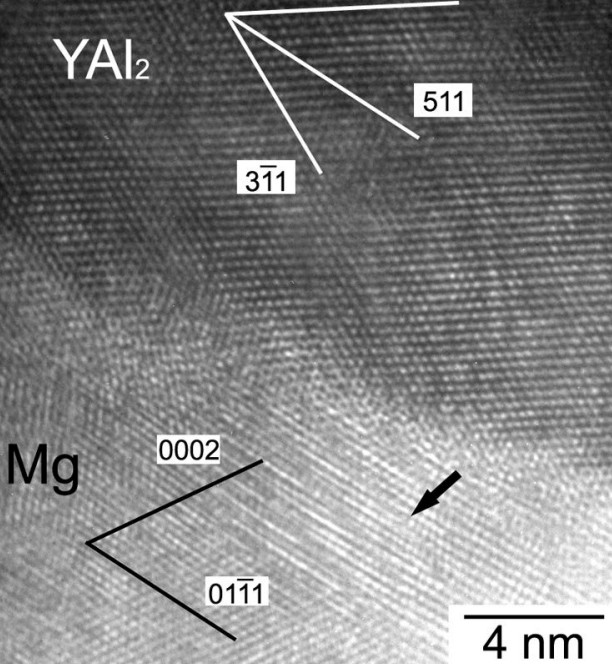


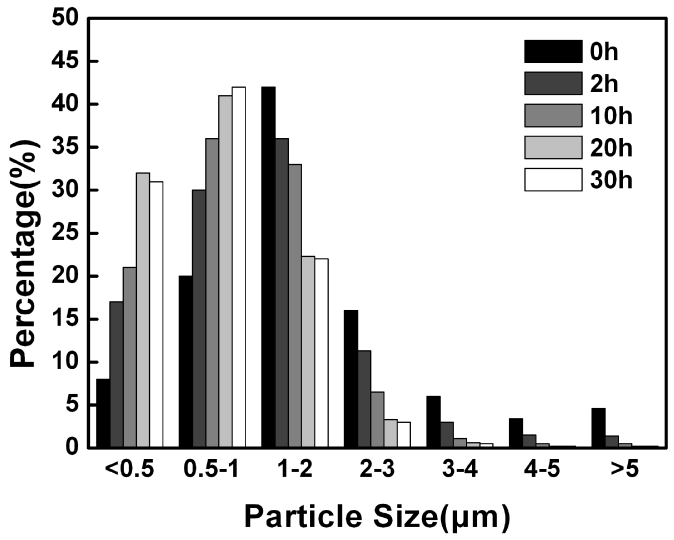




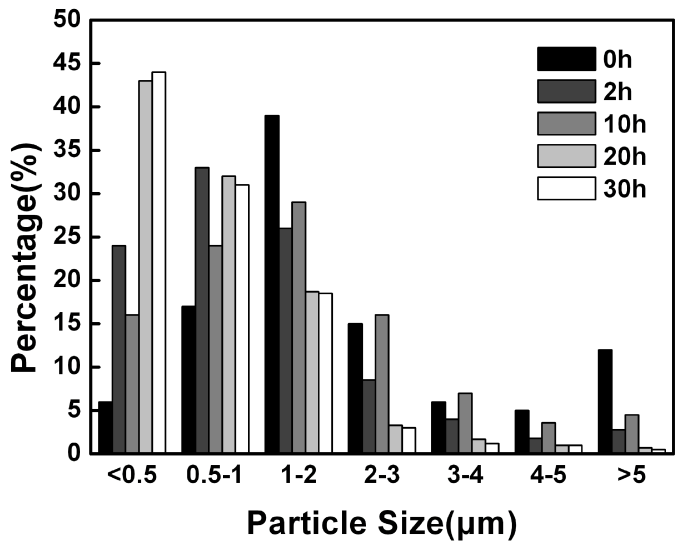




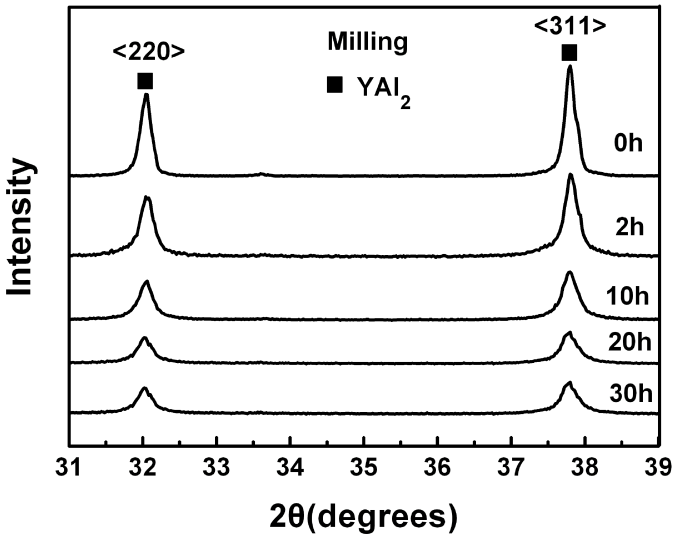




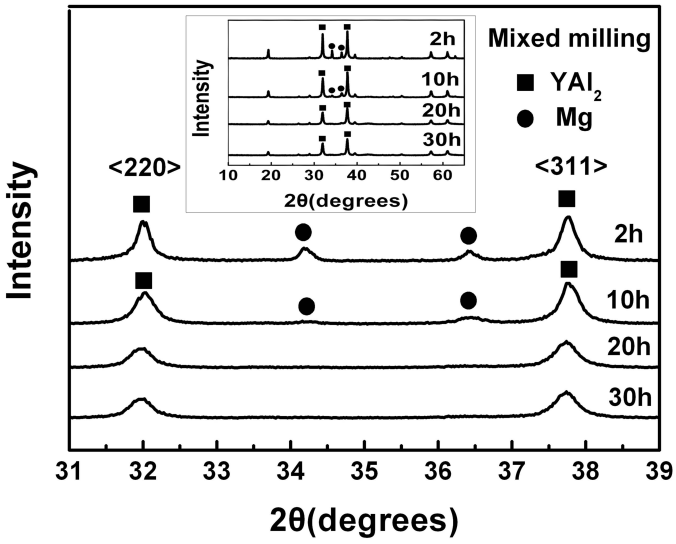




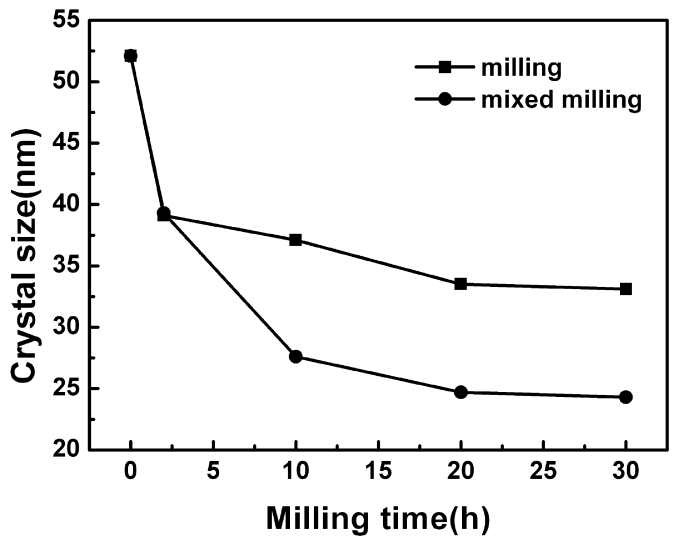




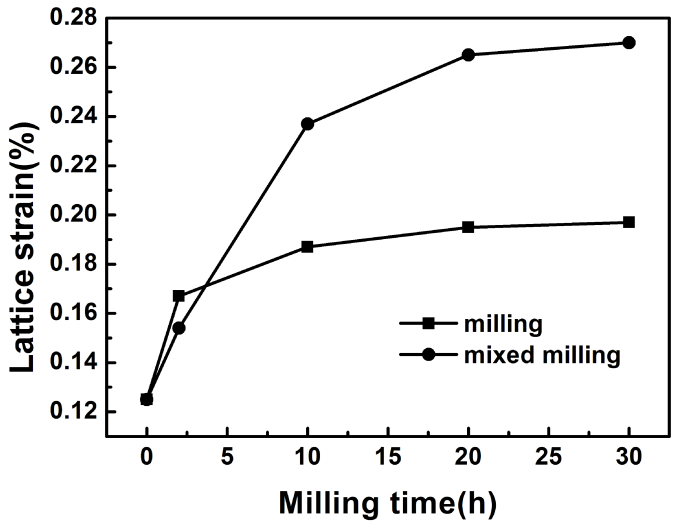

